OPEN ACCESS

Edited by:

Xian-Tao Zeng,

Wuhan University, China

Reviewed by:

Li-Chia Chen,

The University of Manchester,

United Kingdom

Chengfeng Qiu,

Huaihua First People's Hospital, China

Xiao-Feng He,

Heping Hospital Affiliated to Changzhi

Medical College, China

*Correspondence:

Rong-Sheng Zhao

zhaorongsheng@bjmu.edu.cn

${ }^{+}$ORCID:

Zhan-Miao Yi

orcid.org/0000-0001-8575-3770

Specialty section:

This article was submitted to

Pharmaceutical Medicine and Outcomes Research,

a section of the journal

Frontiers in Pharmacology

Received: 26 April 2020 Accepted: 07 September 2020

Published: 02 October 2020

Citation:

YiZ-M, Hu Y, Wang G-R and Zhao R-S (2020) Mapping Evidence of Pharmacy Services for COVID-19 in China.

Front. Pharmacol. 11:555753. doi: 10.3389/fphar.2020.555753

\section{Mapping Evidence of Pharmacy Services for COVID-19 in China}

\author{
Zhan-Miao $\mathrm{Yi}^{1,2,3 \dagger}$, Yang Hu ${ }^{1,2,3,4}$, Guan-Ru Wang ${ }^{1,2,3,4}$ and Rong-Sheng Zhao ${ }^{1,2,3^{*}}$ \\ ${ }^{1}$ Department of Pharmacy, Peking University Third Hospital, Beijing, China, 2 Institute for Drug Evaluation, Peking University \\ Health Science Center, Beijing, China, ${ }^{3}$ Therapeutic Drug Monitoring and Clinical Toxicology Center, Peking University, \\ Beijing, China, ${ }^{4}$ Department of Pharmacy Administration and Clinical Pharmacy, School of Pharmaceutical Sciences, Peking \\ University, Beijing, China
}

Objective: To explore the role of pharmacists and innovation of pharmacy interventions for COVID-19 patients in China.

Methods: We comprehensively searched PubMed and Chinese databases Sinomed, China National Knowledge Infrastructure to identify articles reporting pharmacist interventions and pharmacy services for COVID-19 patients using a predefined search strategy. The search period was from inception to April $7^{\text {th }}$ 2020. We also manually searched the reference list of included articles and websites of important journals with special issues for COVID-19.

Results: A total of 156 articles were identified by applying the search criteria. After screening, 91 articles, with the majority are literature reviews $(n=77,84.62 \%)$ published in Chinese ( $n=83,91.2 \%)$, were included. Pharmacist interventions for COVID-19 patients most commonly related to guidelines or consensus development for the treatment of disease and practice procedure to prevent the spread of COVID-19 $(n=10,10.98 \%)$, the supply of medicines to treat patients with severe respiratory or systematic symptoms related to COVID-19 ( $\mathrm{n}=10,10.98 \%$ ), formulating infections prevention and control strategies related to COVID-19 for pharmaceutical personnel/pharmacy staff ( $n=14$, $15.39 \%)$, new way of delivery pharmacy services and the implementation of new pharmacy services for COVID-19 outbreak ( $n=14,15.39 \%$ ), routine pharmacy services under the restrict limit of COVID-19 outbreak ( $n=39,42.86 \%)$, and case series analysis of treatment regimens using existing, routinely collected data $(n=4,4.40 \%)$.

Conclusion: Pharmacy services have a role in the COVID-19 pandemic control, and there were many rapid changes in response to the pandemic.

Keywords: COVID-19, pharmacy service, guideline development, emergency supply, service model innovation, treatment regimens

\section{INTRODUCTION}

The coronavirus disease 2019 (COVID-19) epidemic began in December 2019 in China and had spread to 210 countries and territories around the world with 4,731,458 confirmed cases as of May $19^{\text {th }} 2020$ (World Health Organization, 2020a). The World Health Organization (WHO) had declared COVID-19 epidemic as a Public Health Emergency of International Concern on January 
$30^{\text {th }} 2020$ (World Health Organization, 2020b). On March $12^{\text {th }}$, the WHO had declared COVID-19 epidemic a "pandemic" worldwide (World Health Organization, 2020c).

After the COVID-19 outbreak, China issued a series of emergency plans and took effective measures to control the pandemic in a timely manner. And the COVID-19 has been well-controlled in China through strenuous efforts during February $1^{\text {st }}$ to April $7^{\text {th }}$. On March $4^{\text {th }}, 21$ provinces in China lowered the emergency response levels. On March $19^{\text {th }} 2020$, China reported no domestic new cases at the first time, indicating the ending of the first prevail peak period of COVID-19 in China. On April $7^{\text {th }}$, the Chinese government put forward guidelines related to actively and orderly promoting the resumption of production (Leading Group of the Central Committee on Response to COVID-19, 2020). However, as China is now facing the risk of COVID-19 rebound and most countries around the world are still at the COVID-19 pandemic lockdown, more evidence and experience are needed to successfully prevent and treat infections (Omer et al., 2020), especially for healthcare practitioners. Due to the government's mobilization ability and Chinese medical personnel's responsibility and courage, medical staff quickly participated in the prevention and treatment of the epidemic. For example, there were more than 42,000 medical staff supporting Hubei province in China (National Health Commission of People's Republic of China, 2020). Meanwhile, medical resources were scientifically scheduled for COVID-19 patients at different stages. Pharmacists, as healthcare practitioner, are actively participating in the fight during the outbreak (Al-Quteimat and Amer, 2020). Pharmacists' important role in preventing and controlling COVID-19 has been highly stressed in International Pharmaceutical Federation (FIP) guidance for pharmacists (International Pharmaceutical Federation, 2020) and the experts consensus of Chinese Pharmaceutical Association (Zhao et al., 2020a). Besides, several studies had indicated that pharmacists have a role in evidence-based therapy, monitoring and management of convalescent plasma therapy during COVID-19 pandemic in addition to the routine pharmaceutical service such as assessing patients' previous medication history, drug allergy history, adverse drug reactions, and drug interactions (Martin et al., 2018; Song Z. W. et al., 2020).

As the forefront of the outbreak, pharmacists in China have responded rapidly to COVID-19. In the FIP guidance, community pharmacists can comfort patients, contact the health department to initiate relevant care programs, inform the public about health information about isolation, diagnosis, and treatment related procedures, and provide evidence-based information (International Pharmaceutical Federation, 2020). In China, pharmaceutical care was provided for COVID-19 patients and the public, and guidelines of clinical therapy and strategy for controlling the pandemic were promptly established and submitted to the International Pharmaceutical Federation (Zhao et al., 2020a). Moreover, many preliminary research for anti-viral treatment drugs were initiated. However, the whole picture of role of pharmacists for COVID-19 was still unclear. As
China is the first country that managed the COVID-19 outbreak, the document of such experiences will be a beneficial lesson for managing the future infectious disease pandemics to come. Mapping the strategies and evidence-based strategies/measures will help further policy decision making. At the same time, the outbreak of COVID-19 has suddenly changed people' daily life and posed challenges to the routine pharmaceutical service. As patients are under quarantine at home or in hospitals, some new ways to deliver pharmaceutical service are necessary when there is no chance of face-to-face consultation between pharmacists and patients.

Thus, we conducted a scoping review to summarize currently published articles by pharmacists, to provide information regarding content and innovation of pharmacy services for COVID-19 in China.

\section{MATERIALS AND METHODS}

The study was conducted following the methodological framework suggested by Arksey and O’Malley (2005).

\section{Search Strategy}

We searched PubMed and two Chinese databases including Sinomed and China National Knowledge Infrastructure from inception to April $7^{\text {th }} 2020$ to identify articles reporting findings related to pharmacy service for COVID-19. On April $7^{\text {th }}$, China announced that most areas in the country were in low risk and published the guidance for the prevention and control measures for getting back to work in different risk areas of the country (The State Council of the People's Republic of China, 2020). The search terms included the following keywords: "COVID-19," "severe acute respiratory syndrome coronavirus 2," "2019nCoV," "SARS-CoV-2," "Novel coronavirus," "nCoV," "Emerging Coronaviruses," "new coronavirus," "pharmacist," "pharmacy," "pharmaceutical care," "pharmaceutical service," and "medication therapy management." Terms were translated into Chinese when searching the Chinese databases. We also manually searched the reference list of the included articles and websites of important journals as a supplementary source for relevant literature, such as Research in Social and Administrative Pharmacy, International Journal of Clinical Pharmacy, Journal of the American Pharmacists Association, American Journal of Hospital Pharmacy, Chinese Pharmaceutical Journal, China Pharmacy, Clinical Medication Journal, and Adverse Drug Reactions Journal with special issues for COVID-19. We included all the relevant publications written in English or Chinese and had no limits on the type of pharmacy service or on the country in which the service was provided. All types of publications were considered, such as original studies, reviews, editorials, commentaries, and conference preceding.

\section{Study Identification and Selection}

Two investigators ( $\mathrm{YH}$ and GR-W) independently screen the references of all retrieved records for potentially relevant articles, beginning with title and abstract screening in the first stage and 
full-text screening in the second. In the title and abstract screening stage, articles appearing to meet the inclusion criteria, or with insufficient information to make a clear judgment, were included in the full-text screening process. We obtained full texts of all these articles for the full-text screening. We included publications if they reported on pharmacy services for COVID-19 patients where either a description of the content or outcomes of pharmacy service was given. All types of publications were included. All disagreements about study selection were resolved through discussion $\backslash$ medicines to treat patients with severe respiratory or systematic symptoms related to COVID-19, 3) formulating infections prevention and control strategies related to COVID-19 for pharmaceutical personnel/ pharmacy staff, 4) new way of delivery pharmacy services and the implementation of new pharmacy services for COVID-19 outbreak, 5) routine pharmacy services under the restrict limit of COVID-19 outbreak, and 6) case series analysis of treatment regimens using existing, routinely collected data.

\section{Data Extraction and Quality Assessment}

Data extraction was performed by the same two investigators (YH and GR-W) using a pre-designed data collection tool. The following information was extracted from included publications: first author, publication date, type of study, content and changes of pharmacy services in response to the pandemic. Two investigators independently assessed the methodological quality of included studies. We evaluate the quality of the eligible guidelines with Appraisal of Guidelines for Research \& Evaluation II (AGREE II) instrument (AGREE Next Steps Consortium, 2017). The methodological quality of eligible observational studies was evaluated with the Joanna Briggs Institute Reviewers' Manual (Moola et al., 2020).

\section{RESULTS}

\section{Study Selection and Characteristics of Included Literatures}

The initial search identified 156 relevant records, with a further two additional records identified through other sources (journal websites). Of these, 68 were excluded after duplicates were removed and title/abstract screening, leaving 94 papers eligible for full-text review. Ninety one articles that met the inclusion criteria were finally included (Bian et al., 2020a; Bian et al., 2020b; Cao et al., 2020; Che et al., 2020; Chen et al., 2020a; Chen et al., 2020b; Chen F. et al., 2020; Chen J. Z. et al., 2020; Chen L. F. et al., 2020; Chen L. P. et al., 2020; Chen M. et al., 2020; Chen Y. W. et al., 2020; Dong et al., 2020; Du et al., 2020; Duan et al., 2020; Gao et al., 2020; Gong et al., 2020a; Gong et al., 2020b; Guo et al., 2020; Gu et al., 2020; Han et al., 2020; He L. L. et al., 2020; He S. Z. et al., 2020; Hu C. J. et al., 2020; Hu Z. Q. et al., 2020; Huang et al., 2020a; Huang et al., 2020b; Huang L. F. et al., 2020; Jin et al., 2020; Li G. H. et al., 2020; Li Q. C. et al., 2020; Lin and Zhang, 2020; Liu and Yan, 2020; Liu X. X. et al., 2020; Liu et al., 2020a; Jin et al., 2020; Li H. et al., 2020; Liu et al., 2020b; Liu X. L. et al., 2020; Liu Y. et al., 2020; Meng et al., 2020; Peng et al.,
2020; Rao et al., 2020; Shao et al., 2020; Shen et al., 2020; Song B. et al., 2020; Song Z. W. et al., 2020; Tan et al., 2020; Therapeutic Drug Monitoring Pharmacists Branch of Chinese Pharmacists Association et al., 2020; Ung, 2020; Wang, 2020; Wang J. W. et al., 2020; Wang N. N. et al., 2020; Wang R. R. et al., 2020; Wang Y. et al., 2020; Wei et al., 2020; Xie et al., 2020; Xiong et al., 2020a; Xiong et al., 2020b; Xu X. H. et al., 2020; Xu Y. X. et al., 2020; Yang Y. Y. et al., 2020; Yang et al., 2020a; Yang et al., 2020b; Yan J. L. et al., 2020; Yan Y. Y. et al., 2020; Yang M. Y. et al., 2020; Yang Y. et al., 2020; Yang C. et al., 2020; Yang L. et al., 2020; Yang L. et al., 2020; Yang Y. H. et al., 2020; Yi et al., 2020; Yin et al., 2020; Ying et al., 2020; Yuan et al., 2020; Zeng et al., 2020; Zhang D. et al., 2020; Zhang J. H. et al., 2020; Zhang L. et al., 2020; Zhang X. Q. et al., 2020; Zhang Y. L. et al., 2020; Zhang Z. H. et al., 2020; Zheng et al., 2020; Zhao et al., 2020a; Zhao et al., 2020b; Zhao et al., 2020c; Zhou H. et al., 2020; Zhou P. X. et al., 2020; Zhou W. et al., 2020; Zhu S. Y. et al., 2020; Zhu Y. G. et al., 2020). Figure 1 provides details of the reasons for excluding articles from this review.

\section{Research Domains, Publication Dates, and Methodological Characteristics}

Most of the publications ( $\mathrm{n}=83,91.2 \%$ ) (Bian et al., 2020a; Bian et al., 2020b; Cao et al., 2020; Che et al., 2020; Chen et al., 2020a; Chen et al., 2020b; Chen F. et al., 2020; Chen J. Z. et al., 2020; Chen L. F. et al., 2020; Chen L. P. et al., 2020; Chen M. et al., 2020; Chen Y. W. et al., 2020; Dong et al., 2020; Du et al., 2020; Duan et al., 2020; Gao et al., 2020; Gong et al., 2020a; Gong et al., 2020b; Gu et al., 2020; Guo et al., 2020; Han et al., 2020; He L. L. et al., 2020; He S. Z. et al., 2020; Hu C. J. et al., 2020; Hu Z. Q. et al., 2020; Huang et al., 2020a; Huang et al., 2020b; Huang L. F. et al., 2020; Jin et al., 2020; Li G. H. et al., 2020; Li Q. C. et al., 2020; Lin and Zhang, 2020; Liu and Yan, 2020; Liu X. X. et al., 2020; Liu et al., 2020b; Liu X. L. et al., 2020; Liu Y. et al., 2020; Peng et al., 2020; Rao et al., 2020; Shao et al., 2020; Shen et al., 2020; Song B. et al., 2020; Tan et al., 2020; Therapeutic Drug Monitoring Pharmacists Branch of Chinese Pharmacists Association et al., 2020; Wei et al., 2020; Wang, 2020; Wang J. W. et al., 2020; Wang N. N. et al., 2020; Wang R. R. et al., 2020; Wang Y. et al., 2020; Xie et al., 2020; Xiong et al., 2020a; Xiong et al., 2020b; Xu X. H. et al., 2020; Xu Y. X. et al., 2020; Yan J. L. et al., 2020; Yan Y. Y. et al., 2020; Yang et al., 2020b; Yang L. et al., 2020; Yang Y. H. et al., 2020; Yang Y. Y. et al., 2020; Yang L. et al., 2020; Yang et al., 2020a; ; Yang M. Y. et al., 2020; Yang Y. et al., 2020; Yang C. et al., 2020; Yi et al., 2020; Yin et al., 2020; Yuan et al., 2020; Zeng et al., 2020; Zhang D. et al., 2020; Zhang J. H. et al., 2020; Zhang L. et al., 2020; Zhang X. Q. et al., 2020; Zhang Y. L. et al., 2020; Zhang Z. H. et al., 2020; Zhao et al., 2020a; Zhao et al., 2020b; Zhao et al., 2020c; Zhou H. et al., 2020; Zhou P. X. et al., 2020; Zhu S. Y. et al., 2020; Zhu Y. G. et al., $2020)$ are in Chinese and few $(n=8,8.8 \%)$ are in English (Song Z. W. et al., 2020; Zhou W. et al., 2020; Zheng et al., 2020; Liu et al., 2020a; Meng et al., 2020; Li H. et al., 2020; Ying et al., 2020; Ung, 2020). The publications mainly focused on routine pharmacy services under the restrict limit of COVID-19 outbreak (42.86\%) (Table 1). Most of articles were published 


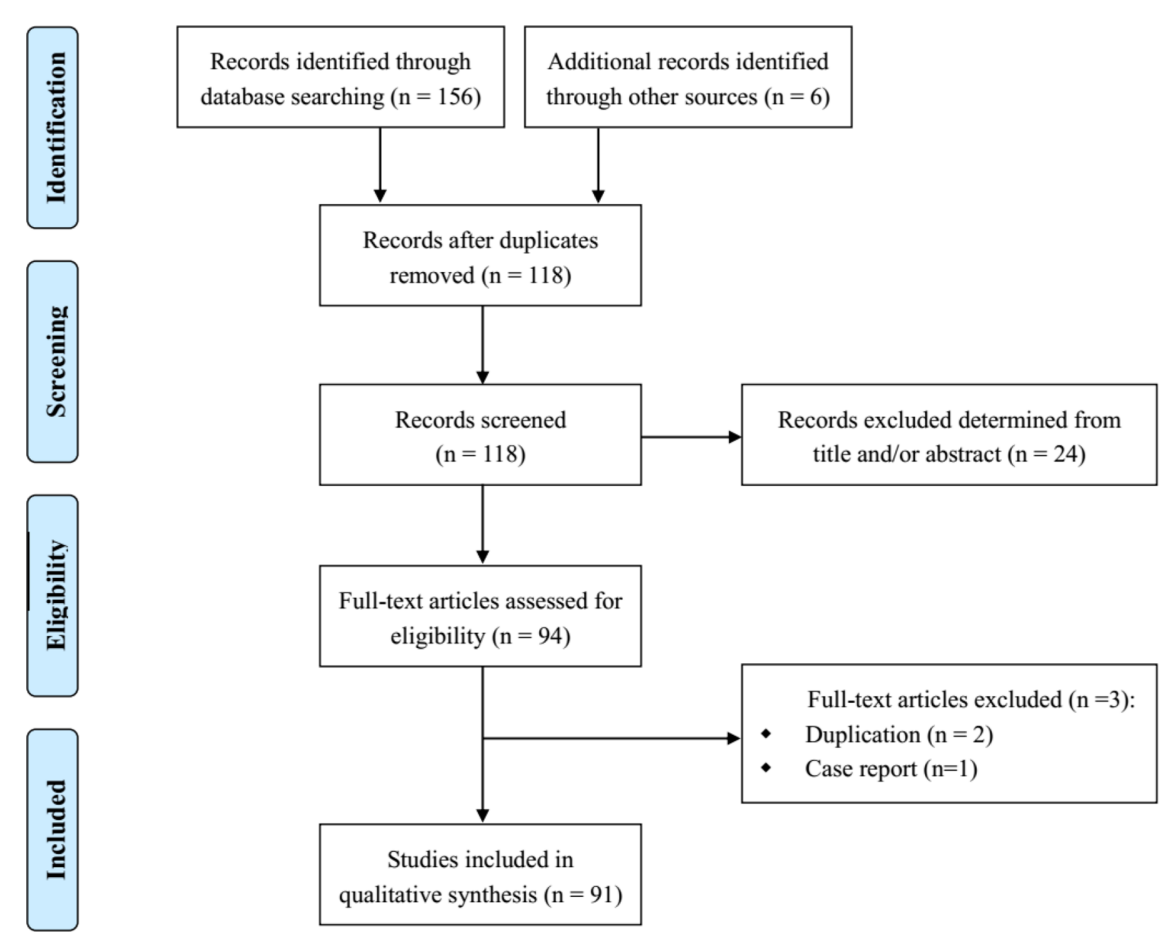

FIGURE 1 | Flow diagram for literature search and study selection.

TABLE 1 | Research domains of included articles.

Research domains

Guideline or consensus development

The supply of medicines for COVID-19

Formulating infections prevention and control strategies related to COVID-19

New way of delivery pharmacy services and new pharmacy services for COVID-19

Routine pharmacy services under the restrict limit of COVID-19 outbreak

Case series analysis of treatment regimens

in March 2020, with increased articles on retrospective analysis of treatment regimens (Figure 2).

We also analyzed the methodological characteristics of the publications in the final sample. The majority of included articles are literature review ( $\mathrm{n}=77,84.62 \%$ ), and others were guidelines/consensus $(\mathrm{n}=10,10.99 \%)$ and original research $(\mathrm{n}=4,4.40 \%)$.

\section{Geographic Distributions of Pharmacy Service Literatures}

Pharmacists from 18 provinces of China published Chinese and English articles on pharmacy service, with pharmacists from Beijing ( $\mathrm{n}=26,28.57 \%$ ) (Dong et al., 2020; Guo et al., 2020; International Pharmaceutical Federation, 2020; Jin et al., 2020; Li H. et al., 2020; Liu and Yan, 2020; Lin and Zhang, 2020; Song Z. W. et al., 2020; Therapeutic Drug Monitoring Pharmacists
Branch of Chinese Pharmacists Association et al., 2020; Xu X. H. et al., 2020; Yan J. L. et al., 2020; Yan Y. Y. et al., 2020; Yang L. et al., 2020; Yang M. Y. et al., 2020; Yang Y. H. et al., 2020; Yi et al., 2020; Yin et al., 2020;Zhang D. et al., 2020; Zhang L. et al., 2020; Zhang Y. L. et al., 2020; Zhang Z. H. et al., 2020; Zhao et al., 2020b; Zhao et al., 2020c; Zheng et al., 2020; Zhou P. X. et al., 2020; Zhou W. et al., 2020), Sichuan ( $=14,15.38 \%)$ (Bian et al., 2020a; Bian et al., 2020b; Chen M. et al., 2020; Du et al., 2020; Gao et al., 2020; Han et al., 2020; He L. L. et al., 2020; Hu C. J. et al., 2020; Hu Z. Q. et al., 2020; Li Q. C. et al., 2020; Liu X. X. et al., 2020; Xiong et al., 2020a; Xiong et al., 2020b; Yang Y. et al., 2020), and Hubei ( $\mathrm{n}=14,15.38 \%$ ) (Chen et al., 2020a; Chen J. Z. et al., 2020; Gong et al., 2020a; Gong et al., 2020b; Gu et al., 2020; Huang et al., 2020a; Huang et al., 2020b; Li G. H. et al., 2020; Liu X. L. et al., 2020; Liu Y. et al., 2020; Yang et al., 2020a; Yang et al., 2020b; Zhou H. et al., 2020) published most of 


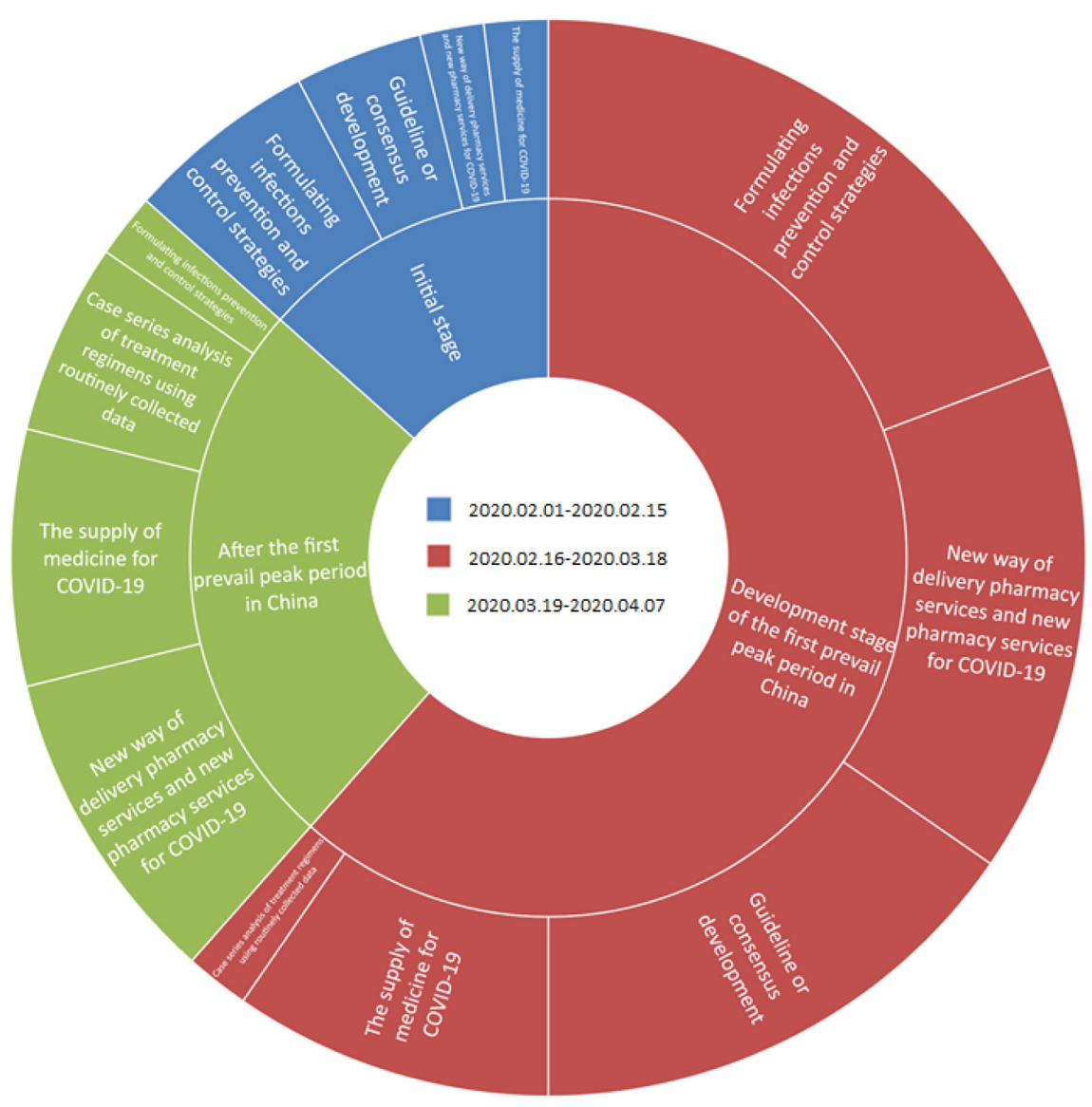

FIGURE 2 | Contents and publication dates of included articles.

the articles (Figure 3). Statistics on the geographic areas of pharmacy workers who published papers in China can explain to a certain extent the differences in the level of medical technology in different regions of China and the speed with which pharmacy workers respond to epidemics.

\section{Contents of Pharmacy Services}

For contents of included 91 articles, 39 articles (42.86\%) were related to routine pharmacy services under the restrict limit of COVID-19 outbreak (Bian et al., 2020a; Cao et al., 2020; Che et al., 2020; Chen et al., 2020a; Chen L. P. et al., 2020; Chen M. et al., 2020; Chen Y. W. et al., 2020; Du et al., 2020; Duan et al., 2020; Guo et al., 2020; Han et al., 2020; Hu Z. Q. et al., 2020; Lin and Zhang, 2020; Li Q. C. et al., 2020; Liu and Yan, 2020; Liu X. X. et al., 2020; Peng et al., 2020; Shao et al., 2020; Song B. et al., 2020; Song Z. W. et al., 2020; Wang, 2020; Wang Y. et al., 2020; Wang R. R. et al., 2020; Xiong et al., 2020a; Xiong et al., 2020b; Yang C. et al., 2020; Yang et al., 2020a; Yang et al., 2020b; Yan J. L. et al., 2020; Yang L. et al., 2020; Yang M. Y. et al., 2020; Yi et al., 2020; Zhang D. et al., 2020; Zhang J. H. et al., 2020; Zhang Y. L. et al., 2020; Zhang Z. H. et al., 2020; Zheng et al., 2020; Zhou W. et al., 2020; Zhu S. Y. et al., 2020), 14 articles (15.39\%) focused on new way of delivery pharmacy services to reduce face-to-face contact using innovative technologies and the implementation of new pharmacy services for COVID-19 outbreak (16.28\%) (Liu et al., 2020a; Meng et al., 2020; Huang L. F. et al., 2020; Yang Y. Y. et al., 2020; Zeng et al., 2020; Bian et al., 2020b; Gao et al., 2020; He L. L. et al., 2020; Gu et al., 2020; Li H. et al., 2020; Gong et al., 2020a; Gong et al., 2020b; Chen F. et al., 2020; Yang Y. et al., 2020), 14 articles (15.39\%) focused on the formulation of infections prevention and control strategies for pharmacy workforce (Chen J. Z. et al., 2020; Chen L. F. et al., 2020; Shen et al., 2020; Tan et al., 2020; Ung, 2020; Wang N. N. et al., 2020; Wei et al., 2020; Yang L. et al., 2020; Yan Y. Y. et al., 2020; Yuan et al., 2020; Zhang X. Q. et al., 2020; Zhou H. et al., 2020; Zhou P. X. et al., 2020), 10 articles (10.99\%) were guidelines or expert consensus (International Pharmaceutical Federation, 2020; Jin et al., 2020; Li G. H. et al., 2020; Therapeutic Drug Monitoring Pharmacists Branch of Chinese Pharmacists Association et al., 2020; Wang J. W. et al., 2020; Yang Y. H. et al., 2020; Zhang L. et al., 2020; Zhao et al., 2020b; Zhao et al., 2020c; Zhu Y. G. et al., 2020), 10 articles (10.99\%) introduced the supply of medicines for COVID-19 during pandemic in China (Dong et al., 2020; He S. Z. et al., 2020; Hu C. J. et al., 2020; Liu et al., 2020b; Liu X. L. 


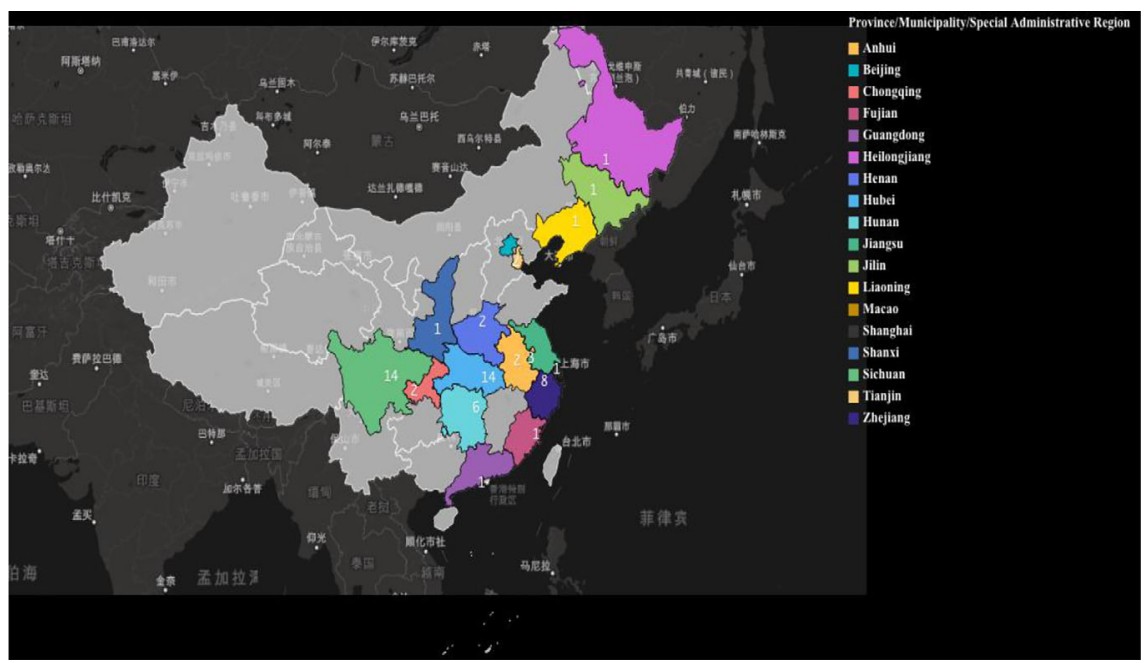

FIGURE 3 | Geographic distributions of pharmacy service articles for COVID-19 in China.

et al., 2020; Liu Y. et al., 2020; Rao et al., 2020; Xie et al., 2020; Xu X. H. et al., 2020; Ying et al., 2020), and 4 articles (4.40\%) were case series analysis of the effectiveness and safety of treatment regimens for COVID-19 (Chen et al., 2020b; Huang et al., 2020a; Huang et al., 2020b; Xu Y. X. et al., 2020) (Figure 4).

\section{Guideline or Consensus Development}

These articles introduced work guidance on drug management and usage in special periods and the plan and response strategy by Chinese pharmacy personnel for COVID-19 pandemic situation from a macro perspective. The domains that scored better were: "scope and purpose" (all included guidelines/ consensus exceeding the cut-off of 70\%) and "clarity and presentation" (5 of 10 included guidelines/consensus exceeding the cut-off of 70\%). Those that scored worse were "stakeholder involvement" and "rigour of development" (none of the included guidelines/consensus exceeding the cut-off of 70\%). Two of the included guidelines/consensus had three domains exceeded the cut-off of 70\% (International Pharmaceutical Federation, 2020; Zhao et al., 2020b), while others had only one or two domains exceeded the cut-off of $70 \%$. Topics of guidelines or expert consensus included practice principles prevention and control strategies for hospital or retail pharmacy $(n=5)$ (International Pharmaceutical Federation, 2020; Wang J. W. et al., 2020; Yang Y. H. et al., 2020; Zhao et al., 2020b; Zhao et al., 2020c), COVID19 drug information compilation $(\mathrm{n}=1)$ (Zhu Y. G. et al., 2020), traditional Chinese medicine $(n=1)$ (Jin et al., 2020), pharmaceutical care for oncology patient population $(\mathrm{n}=1)$ (Li G. H. et al., 2020) COVID-19 patients with complications (n = 1) (Therapeutic Drug Monitoring Pharmacists Branch of Chinese Pharmacists Association et al., 2020), and pharmaceutical care with digital technology $(\mathrm{n}=1)$ (Zhang L. et al., 2020). For example, the "Novel Coronavirus Infection: Expert Consensus on Guidance and Prevention Strategies for Hospital Pharmacists and the Pharmacy Workforce" formulated by Peking University Third Hospital has carried out analysis and summary of relevant data in the process of epidemic prevention and control (Zhu Y. G. et al., 2020). The consensus of the expert was published on February $7^{\text {th }}$, when there were relatively limited information and response measures for COVID-19. The expert consensus summarized information needed to continue pharmacy services during the epidemic, and provided reference and experience for Chinese pharmacy personnel in a timely manner.

\section{The Supply of Medicines for COVID-19}

Topics of these articles covered the emergency management model set up ( $n=5$ ) (Dong et al., 2020; Liu et al., 2020b; Rao et al., 2020; Xie et al., 2020; Ying et al., 2020) and the management of designated hospitals $(n=2)$ (Liu X. L. et al.,

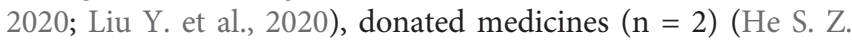
et al., 2020; Xu X. H. et al., 2020), and drug storage ( $\mathrm{n}=1$ ) (Hu C. J. et al., 2020) in hospital pharmacy. For example, the study "Pharmaceutical emergency guarantee difficulties and countermeasures for the prevention and control of outbreak of COVID-19" by Xiangya Hospital published in February summarized four main issues on the supply of medicine for epidemic prevention and control (Liu et al., 2020b).

\section{Formulating Infections Prevention and Control Strategies}

These articles analyze and summarize training of pharmacists during the epidemic, methods of wearing personal protective equipment, disinfection measures, psychological counseling, etc, aiming to reduce risk of infection of pharmacy staff and strengthen the health management of pharmacy staff. Topics covered hospital pharmacists $(n=7)$ (Chen J. Z. et al., 2020; Tan et al., 2020; Yang L. et al., 2020; Yan Y. Y. et al., 2020; Yin et al., 2020; Zhang X. Q. et al., 2020; Zhou P. X. et al., 2020), community pharmacists $(\mathrm{n}=1)$ (Ung, 2020), pharmacy in 


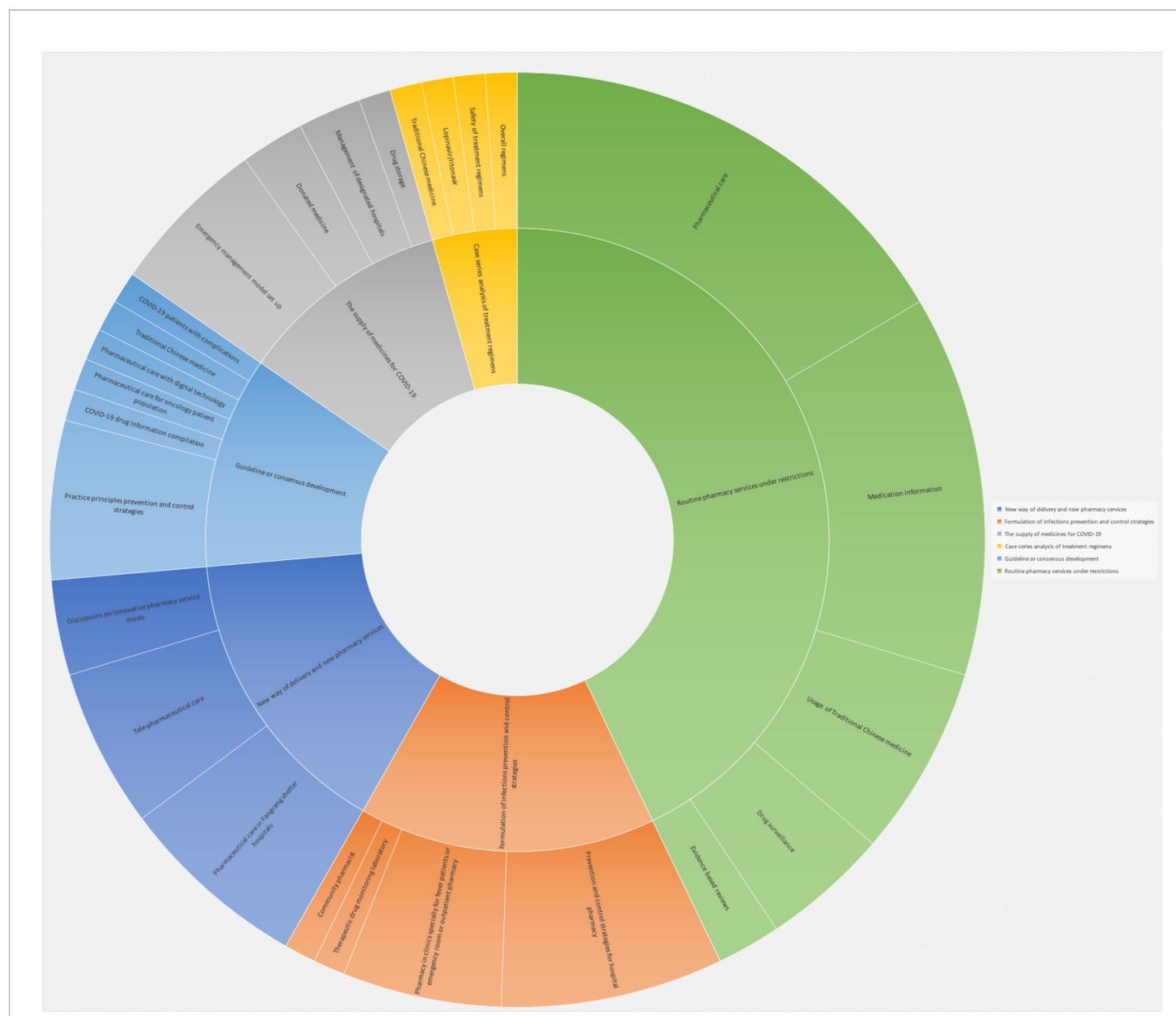

FIGURE 4 | Sunburst plot of pharmacy service articles for COVID-19 in China. *Some articles focused on more than one content in the subgroups.

clinics specially for fever patients or emergency room or outpatient pharmacy $(\mathrm{n}=5$ ) (Chen L. F. et al., 2020; Shen et al., 2020; Wang N. N. et al., 2020; Yuan et al., 2020; Zhou P. X. et al., 2020), therapeutic drug monitoring laboratory $(n=1)$ (Zhou H. et al., 2020). Workforce in the drug monitoring laboratory also has a high risk of infection. One study by pharmacists in Wuhan formulated detailed prevention and control strategies for pharmacists conducting therapeutic drug monitoring (TDM) and provided experience for the development of personal protection, prevention, and control strategies for pharmacists of the same position (Zhou H. et al., 2020). During the epidemic period, pharmacists conducting TDM should handle a large number of blood samples every day, thus the occupational exposure protection and the management of laboratory biological safety were very important.

\section{New Way of Delivery Pharmacy Services and New Pharmacy Services for COVID-19}

Topics of these articles covered pharmaceutical care in Fangcang sheltered hospitals $(n=6)$ (Chen F. et al., 2020; Gong et al., 2020a; Gong et al., 2020b; Gu et al., 2020; Meng et al., 2020; Yang Y. et al., 2020), telepharmaceutical care $(n=5)$ (Gao et al., 2020; He L. L. et al., 2020; Li H. et al., 2020; Yang Y. Y. et al., 2020; Zeng et al., 2020), and other articles on innovative pharmacy service models $(n=3)$ (Liu et al., 2020a; Huang L. F. et al., 2020; Bian et al., 2020b), such as applying models and practical methods to ensure the quality and accessibility of pharmacy services. In the study "The practice and discussion of the online pharmaceutical service mode in square cabin hospital" by pharmacists in the frontline of the Fangcang shelter hospitals explored online methods such as WeChat to provide pharmacy services such as medication reconciliation and 
patient education (Gong et al., 2020b). The shelter hospital, a new public health initiative in a special period, is built by a number of movable modules and has many functions such as emergency treatment and clinical testing. As a necessary functional module for the shelter hospital, the shelter pharmacy played an important role in ensuring the supply of medicines for COVID-19 patients. This article explored new way of delivering pharmacy services for different patients in shelter hospital, and showed the responsibility and creativity of Chinese pharmacists during the pandemic.

\section{Routine Pharmacy Services Under the Restrict Limit of COVID-19 Outbreak}

These articles mainly introduced the key points of patient monitoring during the epidemic, including off-label use, safety use of drugs in clinical trials, and special populations. Topics covered medication information $(n=12)$ (Bian et al., 2020a; Cao et al., 2020; Che et al., 2020; Chen Y. W. et al., 2020; Du et al., 2020; Liu and Yan, 2020; Liu X. X. et al., 2020; Yang M. Y. et al., 2020; Yan J. L. et al., 2020; Zhang J. H. et al., 2020; Zhang Z. H. et al., 2020; Zhou W. et al., 2020), usage of traditional Chinese medicine ( $n=6$ ) (Chen et al., 2020a; Duan et al., 2020; Lin and Zhang, 2020; Yang C. et al., 2020; Wang, 2020; Zhang Y. L. et al., 2020), pharmaceutical care $(n=15)$ (Guo et al., 2020; Hu Z. Q. et al., 2020; Li Q. C. et al., 2020; Shao et al., 2020; Song B. et al., 2020; Song Z. W. et al., 2020; Peng et al., 2020; Wang R. R. et al., 2020; Wang Y. et al., 2020; Xiong et al., 2020a; Xiong et al., 2020b; Yang et al., 2020a; Yang et al., 2020b; Yang L. et al., 2020; Zheng et al., 2020), evidence based review for interferon and lopinavir/ritonavir $(n=2)$ (Chen M. et al., 2020; Yi et al., 2020), and drug surveillance $(\mathrm{n}=4)$ (Chen L. P. et al., 2020; Han et al., 2020; Zhang D. et al., 2020; Zhu S. Y. et al., 2020).

\section{Case Series Analysis of Treatment Regimens Using Routinely Collected Data}

In general, the quality of included case series was good [two scored 16 (Chen et al., 2020b; Xu Y. X. et al., 2020) and another two scored 18 (Huang et al., 2020a; Huang et al., 2020b) of 20 points]. Case-series study by Chen et al. indicated that all patients of 131 cases with COVID-19 treated with traditional Chinese medicine (TCM) Ganlu Xiaodu Decoction and other medicine were cured and discharged (Chen et al., 2020b) and indicated a certain effectiveness for COVID-19. However, the rationality and safety of such therapeutic schedule still need further verification. Another case-series study of 71 patients with COVID-19 by Huang et al. indicated that the combination therapy of $\alpha$-interferon, arbidol, high-dose vitamin $C$, and TCM were effective (Huang et al., 2020a). The remaining two articles retrospectively reviewed the safety of therapeutic schedule for COVID-19 (Huang et al., 2020b; Xu Y. X. et al., 2020). Xu et al. observed the adverse drug reactions of lopinavir/ ritonavir for severe COVID-19 infection in seven patients (Xu Y. $X$. et al., 2020) and indicated that lopinavir/ritonavir could cause serious adverse drug reactions and that safety monitoring was needed. Huang et al. conducted a case-series study of 71 confirmed case of COVID-19 and indicated that inappropriate application of antibiotics for COVID-19 should be avoided and multi-drug combinations could increase the risk of adverse drug reactions (Huang et al., 2020b).

\section{DISCUSSION}

The first evidence map with a total of 91 articles provided a comprehensive summary of articles of pharmacy services in the early stage in response to the COVID-19 in China. Majority are providing routine pharmaceutical care and medication information, especially for special population under the restrict limit of COVID-19 outbreak, prevention and control strategies for hospital pharmacy, clinics specially for fever patients or emergency room, and emergency management model set up. Pharmaceutical care in Fangcang shelter hospitals is new pharmacy service and tele-pharmaceutical care is the main new way to deliver pharmacy service during the pandemic. The included articles were mainly literature reviews in Chinese from three provinces published during March, with Beijing and Sichuan having strong academic capabilities and Hubei the epic center of COVID-19 (Yan et al., 2012).

As the earliest country to fight against COVID-19, the published articles provided important experience of pharmacists in China at the frontline. In the initial stage of the pandemic (February ${ }^{\text {st }} 2020$ to February $15^{\text {th }} 2020$ ), pharmacists acted quickly mainly to formulate infection prevention and control strategies and to give suggestions on providing routine pharmaceutical care in response to the outbreak. The emergency management models of supplying of medicine for COVID-19 began to be set up at the same time. In the development stage of the first prevail peak period of the pandemic in China (February $16^{\text {th }} 2020$ to March $18^{\text {th }} 2020$ ), pharmacists mainly involved in patient management, formulating guidelines and consensus, and updating infections prevention and control strategies as the pandemic situation changes. Meanwhile, pharmacists were actively innovating the new ways of delivery pharmacy services and new pharmacy services for COVID-19. From March $19^{\text {th }} 2020$ to April $7^{\text {th }} 2020$, pharmacists consolidated evidence on the effectiveness of anti-epidemic, resumed medical work properly, and summarized the work experience in the pandemic to better respond to public health emergencies in the future.

However, our study has several limitations. Firstly, the current articles mainly focused on strategies at the beginning and there are limited evidence on the effectiveness and safety of medication for COVID-19 (National Institute for Health and Care Excellence, 2020). Secondly, there are limited, including original, research of pharmacy interventions. As articles on retrospective analysis of treatment regimens increased, more original research on the effectiveness and safety of current treatments is needed, especially for off-label use, outcome evaluation, and real-world data analysis. Thirdly, many high-quality international journals may take longer to publish manuscripts on COVID-19, and thus it is likely to miss out some relevant articles.

Comparing with another scoping review on epidemiology, causes, clinical manifestation and diagnosis, prevention, and control of COVID-19, which indicated $89.2 \%$ articles were 
published in English (Adhikari et al., 2020), pharmacy services articles were mainly published in Chinese, perhaps to facilitate domestic communications among pharmacists during the early stage of the outbreak. Thus an evidence mapping can provide information and experience for pharmacists around the world during global pandemic. A health belief model for understanding the reasons of individuals may or may not act facing a threat to personal or community health was suggested for community pharmacists (Carico et al., 2020). This evidence mapping study can provide information to design a complex intervention following the guidance produced by the Medical Research Council (2019).

\section{CONCLUSIONS}

Pharmacy services have a role in the COVID-19 pandemic control and there were many rapid changes in response to the pandemic. However, more original research, especially outcome evaluation and real-world data analysis, is needed to provide valid and reliable ways for curbing this pandemic

\section{DATA AVAILABILITY STATEMENT}

The raw data supporting the conclusions of this article will be made available by the authors, without undue reservation, to any qualified researcher.

\section{REFERENCES}

Adhikari, S. P., Meng, S., Wu, Y. J., Mao, Y. P., Ye, R. X., Wang, Q. Z., et al. (2020). Epidemiology, causes, clinical manifestation and diagnosis, prevention and control of coronavirus disease (COVID-19) during the early outbreak period: a scoping review. Infect. Dis. Poverty 9, 29. doi: 10.1186/s40249-020-00646-x

AGREE Next Steps Consortium (2017). The AGREE II Instrument [Electronic version]. Available at: http://www.agreetrust.org (Accessed 24.08.2020).

Al-Quteimat, O. M., and Amer, A. M. (2020). SARS-CoV-2 outbreak: How can pharmacists help? Res. Soc. Adm. Pharm. doi: 10.1016/j.sapharm.2020.03.018

Arksey, H., and O'Malley, L. (2005). Scoping studies: towards a methodological framework. Int. J. Soc. Res. Method. 8, 19-32. doi: 10.1080/1364557032000119616

Bian, Y., Wang, Y. Y., Yang, Y., Shu, Y. Q., Xiong, Y., Tong, R. S., et al. (2020a). Rational Use and Pharmaceutical Care of Two Antiviral Drugs. Herald Med. 39, 338-345. doi: 10.3870/j.issn.1004-0781.2020.03.016

Bian, Y., Yang, Z. Y., Xiong, Y., Tong, R. S., Yan, J. F., Long, E. W., et al (2020b). Discussion on clinical pharmaceutical service model in prevention and treatment of corona virus disease 2019. Chin. J. New Drugs Clin. Rem. 39, 212-217. doi: 10.14109/j.cnki.xyylc.2020

Cao, J., Tang, P. J., Zhu, F. F., Zhu, F., Niu, G. H., Song, Q., et al. (2020). Pharmaceutical care of glucocorticoids in the treatment of COVID-19. J. Jiangsu U. Med. 30, 109-113. doi: 10.13312/j.issn.1671-7783.y200080

Carico, R. R., Sheppard, J., and Thomas, C. B. (2020). Community pharmacists and communication in the time of COVID-19: Applying the health belief model. Res. Soc. Adm. Pharm. doi: 10.1016/j.sapharm.2020.03.017

Che, K. K., Liu, X. M., and Hu, C. H. (2020). Retrospective analysis and pharmaceutical care of anti-novel coronavirus drugs based on the latest diagnosis and treatment protocol. J. Southwest U. Natur. Sci. 42, 1-9.

Chen, Y. W., Tang, L. Q., Zhang, S. Y., Wang, M., and Shen, A. Z. (2020). Rational Administration and Pharmaceutical Care of Interferon Alpha Nebulization Therapy in Corona Virus Disease 2019. Chin. J. Hosp. Pharm. 40, 632-635. doi: 10.13286/j.1001-5213.2020.06.07

Chen, L., Liu, F., Wang, X. X., Chen, Y. Y., Song, H. Y., Xia, J. S., et al. (2020a). Medication Rules and Medication Monitoring of 875 Cases of Novel

\section{ETHICS STATEMENT}

Ethical review and approval was not required for the study on human participants in accordance with the local legislation and institutional requirements. Written informed consent for participation was not required for this study in accordance with the national legislation and the institutional requirements.

\section{AUTHOR CONTRIBUTIONS}

Z-MY conceived this review. YH and G-RW identified reports of trials and extracted data. Z-MY, YH and G-RW did all statistical analyses, checked for statistical inconsistency, and interpreted data. R-SZ contributed to data interpretation. Z-MY drafted the report and all other authors (YH, G-RW, and R-SZ) critically reviewed the article. All authors contributed to the article and approved the submitted version.

\section{ACKNOWLEDGMENTS}

We feel grateful for Helen Zhang from Beijing United Family Healthcare and Si-Qian Zheng for help with editing and all the healthcare practitioners for their contributions fighting against COVID-19.

Coronavirus Pneumonia Treated by traditional Chinese Medicine. Chin. J. Exper. Tradit. Med. Form. 26, 35-43. doi: 10.13422/j.cnki.syfjx.20201412

Chen, M., Tong, R. S., Bian, Y., Shu, Y. Q., Yang, Y., Du, S., et al. (2020). Evidencebased Rapid Review on Possibility of Treatment of 2019-nCoV with Subcutaneous $\alpha$-interferon. Herald Med. 39, 483-488. doi: 10.3870/ j.issn.1004-0781.2020.04.0

Chen, L. P., Wu, Y., Jin, C. T., and Wu, S. J. (2020). Pharmaceutical Care of Antiviral Drugs in COVID-19 Patients: Based on Diagnosis and Treatment Scheme (Trial Version 7). Chin. J. Modern App Pharm. 37, 549-554. doi: 10.7539/j.issn.1672-2981.2020.00.000

Chen, F., Qiang, L., Zeng, F., Wang, D. Y., Han, Y., Lv, Y. N., et al. (2020). Analysis and recommendations of coronavirus disease 2019 related medication in Fangcang Hospital with 290 cases. Chin. J. Hosp. Pharm. 40, 1189-1191. doi: 10.13286/j.1001-5213.2020.11.03

Chen, L. F., Xiao, Y., Yu, Y., Yang, H. Y., Shen, T. Y., Song, J., et al. (2020). Prevention and Control Measures of the Hospital Pharmacy in Fever Clinic During the Coronavirus Disease 2019 Epidemic. China Pharmaceut. 29, 18-22. doi: 10.3969/j.issn.1006-4931.2020.05.004

Chen, J. Z., Hu, M. L., Luo, J. W., Zhang, W., and Zhang, D. Y. (2020). Practice of Pharmaceutical Care in Designated Hospital under the Condition of Novel Coronavirus Pneumonia Epidemic. Chin. Pharm. 31, 536-539. doi: 10.6039/ j.issn.1001-0408.2020.05.06

Chen, L., Cheng, Z. Q., Liu, F., Xia, Y., and Chen, Y. G. (2020b). Analysis of 131 cases of COVID-19 treated by Ganlu Xiaodu Decoction. Chin. J. Chin. Mater. Med. 45, 2232-2238. doi: 10.19540/j.cnki.cjcmm.20200322.505

Dong, S. J., Yang, L., Chen, C., Kong, X. W., Cai, Z., Du, Y. W., et al. (2020). Construction of Integrated Emergency Management Model for Novel Coronavirus Pneumonia Epidemic Prevention and Control in Hospital Pharmacy Department. Chin. Pharm. 31, 513-517. doi: 10.6039/j.issn.10010408.2020.05.01

Du, S., Liu, X. X., Yang, Y., Shu, Y. Q., and Chen, M. (2020). Discussion on the application of intestinal microecological regulators in Corona Virus Disease 2019. Adverse Drug React. J. 22, 147-150. doi: 10.3760/cma.j.issn.10085734.2020 .0006 
Duan, H. F., Rong, C. L., and Cui, Y. (2020). Analysis of the Basic Entry Point and Necessity of Traditional Chinese Medicine Clinical Pharmacists Participating in the Prevention and Treatment of COVID-19 Based on Rational Drug Use. Modern Tradit. Chin. Med. Mater. Med. World Sci. Tech. 3, 597-605. doi: 10.11842/wst.20200224009

Gao, Y. Y., Xu, T., Jin, Z. H., Wang, S. M., Long, G. L., Zheng, M. L., et al. (2020). Practice and discussion of outpatient pharmaceutical care based on medical network model during 2019 novel coronavirus disease (COVID-19). Chin. J. Hosp. Pharm. 40, 606-611. doi: 10.13286/j.1001-5213.2020.06.02

Gong, W. J., Wu, S. L., Wu, T. T., Zeng, F., Shi, C., Han, Y., et al. (2020a). Pharmaceutical Care for Coronavirus Disease (COVID-19) Patients in Square Cabin Hospital. Herald Med. 39, 650-653.

Gong, W. J., Zhou, T., Xu, C. F., Xu, J. Q., Liu, Y. H., Han, Y., et al. (2020b). The practice and discussion of online pharmaceutical service mode in square cabin hospital. Chin. J. Hosp. Pharm. 40, 876-879.

Gu, M., Hua, X. L., Chen, J., Zeng, F., Zhou, T., Zhang, Y., et al. (2020). Practice of Pharmacy Administration and Pharmaceutical Care in Jianghan Module Hospital. China Pharmacist 23, 702-706.

Guo, W., Jia, F., Sha, S., Zan, Y. N., and Liu, S. S. (2020). Medical guidance for the treatment of stress-related disorders in patients infected with a novel coronavirus in square cabin hospital. Adverse Drug React. J. 3, 176-1793. doi: 10.3760/cma.j.cn114015-20200222-00146

Han, L. Z., Bian, Y., Tong, R. S., Yan, J. F., Long, E. W., Shu, Y. Q., et al. (2020). Pharmaceutical care strategy for COVID-19 patients with cardiovascular disease. Cent. South Pharm. 18, 591-597.

He, L. L., Jin, Z. H., Xu, X., Gao, Y. Y., Hu, C. Q., Wang, S. Y., et al. (2020). Practice and discussion on pharmaceutical care for the novel coronavirus epidemic in outpatient pharmacy. West China J. Pharm. Sci. 35, 225-227.

He, S. Z., Li, Z. S., Chen, L., Wang, Z. P., Mo, M. C., Xia, X. H., et al. (2020). Exploring the management model of donated drugs during the period of COVID-19. Pharm. Today. 335, 313-315.

Hu, Z. Q., Ma, X., Qi, T. T., Jiang, G., Xiao, H. T., Jiang, Q., et al. (2020). Pharmaceutical Care for Cancer Patients Receiving Antitumor Treatment during the Outbreak of Corona Virus Disease 2019. J. Cancer Cont. Treat 33, 100-105.

Hu, C. J., Zheng, M. L., He, L. L., Zhu, W. W., Guo, Y., Wang, M., et al. (2020). Exploring the Management Model of Donated Drugs by the Department of Pharmacy during COVID-19. West Chin. J. Pharm. Sci. 33, 100-105. doi: 10.3969/j.issn.1674-0904.2020.02.004

Huang, L. F., Yang, J. F., Gao, P., Wang, H. J., Zhu, Z. Y., Ni, Y., et al. (2020). Facing the COVID-19 Outbreak: Pharmaceutical Care Model for Children with Chronic Disease. Chin. J. Modern App. Pharm. 37, 555-559. doi: 10.13748/j.cnki.issn1007-7693.2020.05.007

Huang, L. J., Chen, F. C., Jiang, X. Q., Li, Z. H., Wang, W., Liu, Y. W., et al. (2020a). Clinical characteristics and therapy of novel corona virus pneumonia: 71 cases retrospective analysis. Cent. South Pharm. 18, 739-742.

Huang, L. J., Chen, F. C., Li, Z. H., Li, P., Xiong, L., and Zhou, W. B. (2020b). Analysis on the safety of drug therapy in patients with coronavirus disease 2019. Chin. Pharmacol. Bull. 36, 30-31.

International Pharmaceutical Federation (2020). Coronavirus SARS-CoV-2 outbreak: Information and interim guidelines for pharmacists and the pharmacy workforce. Chin. Pharm. J. 55, 249-267. doi: 10.11669/ cpj.2020.04.001

Jin, Y., Kun, L. W., and Yan, D. (2020). Consensus on the safe and rational use of early intervention Chinese patent medicines in the novel corona-virus pneumonia (COVID-19) (Beijing). Chin. J. Hosp. Pharm.

Leading Group of the Central Committee on Response to COVID-19 (2020). Guiding opinions of the central leading group on COVID-19 to proactively and orderly promote the resumption of work while effectively preventing and controlling the outbreak. Available at: http://www.gov.cn/zhengce/content/ 2020-04/09/content_5500698.htm (Accessed 19.05.2020).

Li, G. H., Zhai, Q., Huang, H. B., Liu, D., Wu, D. Y., Jin, Y., et al. (2020) Expert group of cancer branch of Chinese Pharmacological Society Professional Committee of Drug-induced Diseases. Impact and management recommendations of drug therapy for tumor patients during the epidemic of Novel coronavirus pneumonia. Adverse Drug React. J. 22, 139-141. doi: $10.3760 / \mathrm{cma}$.j.issn.1008-5734.2020.0004
Li, Q. C., Xie, F. Q., Guo, X. R., Jiang, Q., Wang, H. J., Liu, C., et al. (2020). Comprehensive Pharmaceutical Care for Novel Coronavirus Pneumonia. Chin. J. Hosp. Pharm.

Li, H., Zheng, S., Liu, F., Liu, W., and Zhao, R. (2020). Fighting against COVID-19: Innovative strategies for clinical pharmacists. Res. Soc. Adm. Pharm. doi: 10.1016/j.sapharm.2020.04.003

Lin, Z. J., and Zhang, B. (2020). Strategy of pharmaceutical care services for clinical Chinese pharmacists in novel coronavirus pneumonia. Chin. J. Chin. Mater. Med. 45, 1259-1262. doi: 10.19540/j.cnki.cjcmm.20200211.501

Liu, Q. Y., and Yan, S. Y. (2020). A review of researches and custodial care of chloroquine used in coronavirus infections. Adverse Drug React. J. doi: 10.3760/cma.j.cn114015-20200224-00158

Liu, X. X., Shen, P. X., Du, S., Yang, Y., Shu, Y., Bian, Y., et al. (2020). Rational Use and Pharmaceutical Care of Thymosin Immunomodulators for Novel Coronavirus Pneumonia. Herald Med. 3, 197-200. doi: 10.3870/j.issn.10040781.2020.04.006.

Liu, S., Luo, P., Tang, M., Hu, Q., Joseph, P. P., Sun, S. S., et al. (2020a). Providing pharmacy services during the coronavirus pandemic. Int. J. Clin. Pharm. 42, 299-304. doi: 10.1007/s11096-020-01017-0

Liu, S., He, G. F., Du, J., Wang, D., Shi, C., Huang, Q., et al. (2020b). Pharmaceutical emergency guarantee difficulties and countermeasures for the prevention and control of out-break of Corona Virus Disease 2019(COVID-19). Chin. J. Hos. Pharm. 40, 243-249. doi: 10.13286/j.1001-5213.2020.03.01

Liu, X. L., Liu, Y., Qiu, L., Luo, P., Jin, J. J., Zheng, J. L., et al. (2020). Pharmaceutical administration practice during prevention and treatment of COVID-19. Chin. J. Hosp. Adm. 4, 324-327. doi: 10.3760/cma.j.cn11222520200302-00440

Liu, Y., Qiu, L., Liu, X. L., Yang, J. W., Zhang, C. L., Wang, L., et al. (2020). Practice of Pharmaceutical Management and Pharmaceutical Care in the Designated Hospital of COVID-19. Herald Med. 39, 522-527. doi: 10.3870/j.issn.10040781.2020.04.017

Martin, P., Tamblyn, R., Benedetti, A., Ahmed, S., and Tannenbaum, C. (2018). Effect of a pharmacist-led educational intervention on inappropriate medication prescriptions in older adults: The D-PRESCRIBE randomized clinical trial. JAMA 320, 1889-1898. doi: 10.1001/jama.2018.16131

Medical Research Council (2019). Developing and evaluating complex interventions: Following considerable development in the field since 2006, MRC and NIHR have jointly commissioned an update of this guidance to be published in 2019. Available at: http://www.mrc.ac.uk/complexinterventionsguidance (Accessed 13.04.2020).

Meng, L., Qiu, F., and Sun, S. (2020). Providing pharmacy services at cabin hospitals at the coronavirus epicenter in China. Int. J. Clin. Pharm. 42, $305-$ 308. doi: 10.1007/s11096-020-01020-5

Moola, S., Munn, Z., Tufanaru, C., Aromataris, E., Sears, K., Sfetcu, R., et al (2020). "Chapter 7: Systematic reviews of etiology and risk," in JBI Manual for Evidence Synthesis. JBI. Eds. E. Aromataris and Z. Munn Available at: https://synthesismanual.jbi.global. doi: 10.46658/JBIMES-20-08

National Health Commission of People's Republic of China (2020). Press conference of the joint defense and joint control mechanism of the State Council. Available at: http://www.nhc.gov.cn/xcs/s3574/202005/ e78dfc196504497586f324f0d9a5bc36.shtm (Accessed 19.05.2020).

National Institute for Health and Care Excellence (2020). COVID-19 rapid guideline: critical care in adults. Available at: https://www.nice.org.uk/ guidance/ng159 (Accessed 10.05.2020).

Omer, S. B., Malani, P., and Del Rio, C. (2020). The COVID-19 Pandemic in the US: A Clinical Update. JAMA 323, 1767-1768. doi: 10.1001/jama.2020.5788

Peng, L. L., Liu, X., Xie, F., and Ji, B. (2020). Analysis of influencing factors of hyperglycemia in patients with coronavirus disease 2019 and diabetes. Chin. J. Clin. Pharmacol. 36, 926-929. doi: 10.13699/j.cnki.1001-6821.2020.07.055

Rao, Y. F., Guo, J. H., and Liao, J. (2020). Hospital pharmacy administration and pharmaceutical care in the prevention and control of corona virus disease-19. Chin. J. Hosp. Pharm. 40, 726-729. doi: 10.13286/j.1001-5213.2020.07.02

Shao, M. M., Zhao, H. M., Chen, J. Y., and Yu, Y. X. (2020). Rational use and pharmaceutical care of lopinavir/ritonavir in the treatment of patients with corona virus disease 2019. Chin. J. Hosp. Pharm. 40, 753-756. doi: 10.13286/ j.1001-5213.2020.07.08

Shen, A. Z., Wu, Y. Q., Zhang, S. Y., Yan, H., Lu, S. S., Guo, A. P., et al. (2020). Prevention and control strategy and pharmaceutical care in outpatient 
department for COVID-19. Chin. J. Hosp. Pharm. 40, 1603-1606+1683. doi: 10.13286/j.1001-5213.2020.15.01

Song, Z. W., Hu, Y., Zheng, S. Q., Yang, L., and Zhao, R. S. (2020). Hospital pharmacists' pharmaceutical care for hospitalized patients with COVID-19: Recommendations and guidance from clinical experience. Res. Soc. Adm. Pharm. doi: 10.1016/j.sapharm.2020.03.027

Song, B., Dong, S. C., and Wang, M. (2020). Pharmaceutical care of antiviral drugs for COVID-19 in the elderly. Chin. J. Hosp. Pharm. 40, 748-752. doi: 10.13286/ j.1001-5213.2020.07.07

Tan, S. L., Xu, P., and Zhu, Y. G. (2020). Protection of hospital pharmacy related personnel under the COVID-19 epidemic. Cent. South Pharm. 18, 335-336. doi: 10.7539/j.issn.1672-2981.2020.02.038

The State Council of the People's Republic of China (2020). Notice on the issuance of guidance for the prevention and control measures for getting back to work in different risk areas of the country. Available at: http://www.gov.cn/zhengce/ content/2020-04/09/content_5500685.htm (Accessed 19.05.2020).

Therapeutic Drug Monitoring Pharmacists Branch of Chinese Pharmacists Association, Hospital Pharmacy Branch of China Association of Chinese Medicine, Emergency Medicine Branch of Chinese Geriatrics Society, Cardiovascular Medicine Branch of Chinese Society of Cardiothoracic and Vascular Anesthesiology, Clinical Toxicology Professional Committee of Chinese Society of Toxicology and Drug induced Diseases Professional Committee of Chinese Pharmacological Society, et al (2020). Guidelines on drug treatment and pharmaceutical care for novel coronavirus pneumonia and common complication. Adverse Drug React. J. 3, 121-129. doi: 10.3760/ cma.j.cn114015-20200304-00211

Ung, C. O. L. (2020). Community pharmacist in public health emergencies: Quick to action against the coronavirus 2019-nCoV outbreak. Res. Soc. Adm. Pharm. 16, 583-586. doi: 10.1016/j.sapharm.2020.02.003

Wang, Y., Tian, D. L., Sun, Y. Y., Bai, Y. L., and Zhu, L. Q. (2020). Pharmaceutical Care for Children in Therapy of Novel Coronavirus Pneumonia. Chin. J. Hosp. Pharm. 40, 593-605. doi: 10.13286/j.1001-5213.2020.06.01

Wang, R. R., Xu, Q., Li, L., Wang, X. J., Jiang, S. P., and Lu, X. Y. (2020). Pharmacological care strategy for antivirals in patients with COVID-19 complicated by underlying disorders. Chin. J. Hosp. Pharm. 40, 612-616. doi: $10.13286 / j .1001-5213.2020 .06 .03$

Wang, J. W., Guan, Y., Cao, S. S., Chen, S. N., Zhao, J. Y., Zhang, W., et al. (2020). SARS-CoV-2 infection: Expert consensus on guidance and prevention and control strategies of retail drugstore work. Chin. Pharm. J. 55, 278-283. doi: $10.11669 /$ cpj.2020.04.003

Wang, N. N., Duan, X. P., Mei, Z. H., Gong, Z. C., and Liu, S. (2020). Prevention and Control Strategies of the Emergency Pharmacy in Large Third-Class A Hospitals During the Coronavirus Disease 2019 Epidemic. China Pharmaceut. 29, 15-18. doi: 10.3969/j.issn.1006-4931.2020.05.003

Wang, X. Y. (2020). Application and pharmaceutical care of traditional Chinese medicine injections recommended by guideline in treatment of corona virus disease 2019. Chin. J. Hosp. Pharm. 40, 847-851. doi: 10.13286/j.10015213.2020.08.02

Wei, L., Li, M. M., and Chen, L. (2020). SARS-CoV-2 infection guideline for pharmacy construction and prevention and control strategies. Pharm. Today.

World Health Organization (2020a). Coronavirus disease (COVID-19) situation report-120. Available at: https://www.who.int/docs/default-source/ coronaviruse/situation-reports/20200519-covid-19-sitrep-120.pdf?sfvrsn= 515cabfb_2 (Accessed 19.05.2020).

World Health Organization (2020b). Rolling updates on coronavirus disease (COVID-19): WHO characterizes COVID-19 as a pandemic. Available at: https://www.who.int/emergencies/diseases/novel-coronavirus-2019/events-asthey-happen (Accessed 07.04.2020).

World Health Organization (2020c). Rolling updates on coronavirus disease (COVID-19): WHO characterizes COVID-19 as a pandemic. Available at: https://www.who.int/emergencies/diseases/novel-coronavirus-2019/events-asthey-happen (Accessed 25.03.2020).

Xie, Y. L., Chang, G. Z., Peng, X. D., Liu, Y. N., Jia, S. J., Li, Z. J., et al. (2020). Emergency plan of hospital pharmacy administration for prevention and control of Corona Virus Disease 2019 (Central South Pharmacy). 18, 1-6.

Xiong, Y., Bian, Y., Jiang, M., Tong, R. S., Yan, J. F., Long, E. M, et al. (2020a). Pharmaceutical services for prevention and treatment of venous thrombosis associated with corona virus disease 2019 (COVID-19). Chin. J. Hosp. Pharm. 40, 857-863. doi: 10.13286/j.1001-5213.2020.08.04

Xiong, Y., Jiang, M., Bian, Y., Ling, W., Tong, R. S., Yan, J. F., et al. (2020b). Pharmaceutical care of corona virus disease 2019 associated circulatory system thrombus prevention and treatment. West China J. Pharm. Sci.

Xu, X. H., Yang, L., Chen, C., Zhai, S. D., and Zhao, R. S. (2020). Management strategy on donated medicines for COVID-19 prevention and control. Chin. Pharm. J. 55, 700-703. doi: 10.11669/cpj.2020.09.006

Xu, Y. X., Shen, L. H., Han, W. C., Xie, B. C., He, R. R., and Ding, S. B. (2020). Pharmaceutical care of lopinavir/ritonavir in the treatment of critically coronavirus disease 2019. Chin. J. Clin. Pharmacol. 36, 922-925. doi: 10.13699/j.cnki.1001-6821.2020.07.054

Yan, Y. Y., Yi, Z. M., and Zhai, S. D. (2012). Publication and Quality of Systematic Reviews/Meta-Analyses Conducted by Hospital Pharmacists in China. Chin. J. Evid. Based. Med. 12, 92-97.

Yan, J. L., Pang, W. Y., Wang, Q. Y., and Zhao, Z. G. (2020). Feasibility and Clinical Evaluation of Lopinavir/Ritonavir in the Treatment of the Severe Acute Respiratory Syndrome-Coronavirus-2. China Pharmaceut. 29, 16-20. doi: $10.3969 / j . i s s n .1006-4931.2020 .06 .004$

Yan, Y. Y., Yuan, X. N., Yang, Y. H., Yang, L., Liu, F., Zhai, S. D., et al. (2020). Exposure Protection Countermeasures for Novel Coronavirus Infection in Hospital Pharmaceutical Staff. China Pharm. 31, 523-527. doi: 10.6039/ j.issn.1001-0408.2020.05.03

Yang, M. Y., Gao, Y. Y., Zou, Y. J., and Zheng, Y. (2020). Pharmacological recommendations on the off-label use of Lopinavir/ritonavir for treatment of coronavirus disease 2019. Chin. J. Hosp. Pharm. 40, 617-621. doi: 10.13286/ j.1001-5213.2020.06.04

Yang, Y., Zhu, Y. L., Lian, J. P., Liu, W., Su, D., Cheng, Z. J., et al. (2020). Discussion on Pharmacy Management and Pharmaceutical Care Mode in Square Cabin Hospital. Herald Med. 39, 518-521. doi: 10.3870/j.issn.10040781.2020.04.016

Yang, C., Yuan, L., Liu, C. Y., Shi, J. H., Wang, P., and Luo, M. H. (2020). Rational use and pharmaceutical care of Chinese patent medicines based on diagnosis and treatment plan for Corona Virus Disease 2019. J. Jinan U. Natur. Sci. Med. 41, 137-143. doi: 10.11778/j.jdxb.2020.02.007

Yang, L., Chen, Y., Huang, J. L., Zhang, Y., Li, X. X., Sun, X. P., et al. (2020). Pharmaceutical Care of Elderly Patients with the Coronavirus Disease 2019. China Pharmaceut. 29, 46-49. doi: 10.3969/j.issn.1006-4931.2020.05.010

Yang, C. X., Li, S. J., Shi, S. J., Liu, Y. N., Zhou, J. L., Zhang, Y., et al. (2020a). Rational drug use and pharmaceutical care strategies under COVID-19 epidemic. Chin. J. Hosp. Pharm. 40, 1071-1076. doi: 10.13286/j.1001-5213.2020.10.01

Yang, C. X., Li, S. J., Diao, C. D., Zhou, J. L., Shi, S. J., Liu, Y. N., et al. (2020b), Severe and Critical Patients with COVID-19 Pneumonia: Standardized Nutrition Therapy and Pharmaceutical Care. Herald Med.

Yang, Y. Y., Chen, S. B., and Lu, X. Y. (2020). Study on the strategy and application of anticoagulant pharmaceutical care during Coronavirus Disease 2019 (COVID-19). Chin. J. Hosp. Pharm. 40, 864-868. doi: 10.13286/j.10015213.2020.08.05

Yang, Y. H., Yan, Y. Y., and Zhai, S. D. (2020). Recommendations on the work of the pharmaceutical department of medical institutions in response to COVID-19 (second edition) Clin. Med. J.18, 1-3. doi: 10.3969/j.issn.1672-3384.2020.02.001

Yang, L., Xu, X. H., Chen, C., Yang, G., and Chen, L. H. (2020). Novel Coronavirus Infection Response: Prevention and Control Strategies Based on Drug, Material Supply and Emergency Management. Chin. Pharm. 31, 517-522. doi: 10.6039/ j.issn.1001-0408.2020.05.02

Yi, Z. M., Guo, H., Qi, S. B., Zhou, T. T., and Zhao, R. S. (2020). Evidence-based Pharmaceutical Practice Responding for Novel Coronavirus Pneumonia Epidemic. Chin. Pharm. 31, 527-531. doi: 10.6039/j.issn.1001-0408.2020.05.04

Yin, Y. Q., Ren, Z. Y., Shi, W. L., Zhao, Y., Yang, L., Zhao, R. S., et al. (2020). Establishment of Hospital Pharmacy Prevention and Control Strategies for Novel Coronavirus Infection Based on 5M1E Analysis Method. Chin. Pharm. 31, 532-535. doi: 10.6039/j.issn.1001-0408.2020.05.05

Ying, W., Qian, Y., and Kun, Z. (2020). Drugs supply and pharmaceutical care management practices at a designated hospital during the COVID-19 epidemic. Res. Soc. Adm. Pharm. doi: 10.1016/j.sapharm.2020.04.001

Yuan, D. D., Chen, Y. Y., Wang, B. J., Ma, Q., Yang, J. F., Lou, H. K., et al. (2020). The pharmaceutical practice for the prevention and control of Corona Virus 
Disease 2019(COVID-19)in the fever pharmacy. Chin. J. Hosp. Pharm. 40, 869-872. doi: 10.13286/j.1001-5213.2020.08.06

Zeng, D. Y., Huang, P. F., Ke, M., Lin, C. H., and Lin, R. F. (2020). Practice and thinking of developing pharmaceutical care with the help of Internet hospital under the outbreak of COVID-19. Adverse Drug React. J. doi: 10.3760/ cma.j.issn.1008-5734.2020.0010

Zhang, Z. H., Wang, Q. Y., and Zhao, Z. G. (2020). Application, evaluation and pharmaceutical care of ribavirin in the treatment of viral diseases. Chin. J. Hosp. Pharm.

Zhang, J. H., Zhu, L. Q., Liu, Z. Y., and Liu, Y. Y. (2020). Pharmacological recommendations on tocilizumab for the treatment of COVID-19. Chin. J. Hosp. Pharm. 40, 721-725. doi: 10.13286/j.1001-5213.2020.07.01

Zhang, Y. L., Zhao, W., Jin, M. Y., Gui, Y., Zhang, Q., Gong, C. L., et al. (2020). Pharmaceutical Care of Traditional Chinese Medicine in Preventing and Treating the Coronavirus Disease 2019. China Pharmaceut. 29, 27-34. doi: 10.3969/j.issn.1006-4931.2020.05.006

Zhang, D., Lv, J. T., Zhang, B., Zhang, X. M., and Lin, Z. J. (2020). Pharmacovigilance study on drug-induced cardiac injury during treatment of COVID-19. Chin. J. Chin. Mater. Med. 45, 2275-2286. doi: 10.19540/j.cnki.cjcmm.20200322.503

Zhang, L., Zhang, K., and Chu, Y. Q. (2020). Expert Consensus on Accelerating the Development of Intelligent Pharmaceutical Care during the Epidemic of Corona Virus Disease 2019 (1st edition) Clin. Med. J. 18, 4-9 doi: 10.3969/ j.issn.1672-3384.2020.02.002

Zhang, X. Q., Shen, T. Y., Sun, J., Lu, X. Y., Huang, M. Z., Zheng, D. S., et al. (2020). Practice and Thinking of Hospital Pharmacy Administration Measures During COVID-19 Epidemic. Chin. J. Modern Appl. Pharm. 37, 536-541. doi: 10.13748/j.cnki.issn1007-7693.2020.05.004

Zhao, R. S., Yang, Y. Y., Yang, L., Li, Z. J., Liu, F., Ren, Z. Y., et al. (2020a). Novel Coronavirus Infection: Expert Consensus on Guidance and Prevention Strategies for Hospital Pharmacists and the Pharmacy Workforce. Chin. Pharm. J. 55, 268-277. doi: 10.11669/cpj.2020.04.002

Zhao, R. S., Yang, Y. H., Yang, L., Li, Z. J., Liu, F., Ren, Z. Y., et al. (2020b). Guidance and management strategy of pharmaceutical work for prevention and control of COVID-19. Chin. Pharm. J.

Zhao, R. S., Yang, Y. H., Yang, L., Li, Z. J., Liu, F., Ren, Z. Y., et al. (2020c). Interpretation of Novel Coronavirus Infection: Expert Consensus on Guidance and Prevention Strategies for Hospital Pharmacists and the Pharmcy
Workforce. Chin. Pharm. 31, 385-389. doi: 10.6039/j.issn.10010408.2020.04.01

Zheng, S. Q., Yang, L., Zhou, P. X., Li, H. B., Liu, F., and Zhao, R. S. (2020). Recommendations and guidance for providing pharmaceutical care services during COVID-19 pandemic: A China perspective. Res. Soc. Adm. Pharm. doi: 10.1016/j.sapharm.2020.03.012

Zhou, W., Liu, Y. S., Tian, D. D., Wang, C., Wang, S., Cheng, S., et al. (2020). Potential benefits of precise corticosteroids therapy for severe $2019-\mathrm{nCoV}$ pneumonia. Signal Transd. Target. Ther. 5, 18. doi: 10.1038/s41392-0200127-9

Zhou, H., Hu, X. H., Huang, X., Cheng, F., Cao, F., Han, Y., et al. (2020). Prevention and Control Strategy of Therapeutic Drug Monitoring Laboratory During the COVID-19 Epidemic. Herald Med. 39, 330-333. doi: 10.3870/ j.issn.1004-0781.2019.03.014

Zhou, P. X., Yang, L., and Zhao, R. S. (2020). A review on the pharmaceutical management, prevention, control and pharmacotherapy for corona virus disease 2019 in China. Clin. Med. J. 18, 34-39. doi: 10.3969/j.issn.16723384.2020.02.007

Zhu, S. Y., Liu, Y., Chen, C. Y., Ding, X. F., and Xu, P. (2020). Anti-SARS-CoV-2 Drugs Induced QT Interval Prolongation: A Literature Review and Pharmaceutical Care. Chin. J. Modern App Pharm. 37, 560-563. doi: 10.13748/j.cnki.issn10077693.2020.05.008

Zhu, Y. G., Deng, Z. W., Liu, L. H., Liu, X. H., Li, X. Z., Chen, W. H., et al. (2020) Drug information compilation of diagnosis and treatment program of COVID19. 1st ed. Central South Pharmacy. Available at: http://kns.cnki.net/kcms/ detail/43.1408.R.20200221.0859.002.html.

Conflict of Interest: The authors declare that the research was conducted in the absence of any commercial or financial relationships that could be construed as a potential conflict of interest.

Copyright (c) $2020 \mathrm{Yi}, \mathrm{Hu}$, Wang and Zhao. This is an open-access article distributed under the terms of the Creative Commons Attribution License (CC BY). The use, distribution or reproduction in other forums is permitted, provided the original author(s) and the copyright owner(s) are credited and that the original publication in this journal is cited, in accordance with accepted academic practice. No use, distribution or reproduction is permitted which does not comply with these terms. 